\title{
Community Capital Management and Non-Institutional Debt Resolution by the Ban Pan Din Yen Savings Group for Production, Moo 9, Tambon Sae O, Wattana Nakorn District, Sakaeo Province
}

\author{
Dr.Vallop Supthpun \\ Lecturer in Graduate School of Public Administration, Burapha University \\ Doctor of Philosophy, Public Administration \\ (E-mail: vallop@buu.ac.th)
}

\begin{abstract}
This qualitative research aimed to investigate the successful methods and approaches employed by the Ban Din Yen Savings Group for Production, Moo 9, Tambon Sae O, Wattana Nakorn District, Sakaeo Province in resolving the problem of non-institutional debt. interviews and group discussions were used with a research sample of 30 informants comprising 11 community leaders and the Ban Pan Din Yen Savings Group for Production committee members, and 19 non-institutional borrowers in the village. Analytical induction and content analysis were used for data analysis. The study revealed that self-reliance and the use of all types of community capital mainly contributed to the community's success in resolving non-institutional debt.
\end{abstract}

Keywords: Community Capital; Saving Groups for Production; Management; Non-institutional Debt

\section{Background and the Significance of the Problem}

The public living hardship caused by their debts has become so pressing that on November 2009 the government started the project titled "Transfer of Non-institutional Debt to Meet New Life" offering the opportunity to non-institutional borrowers (whose debt not exceeding 200,000 baht) to register their debts to the government saving banks and the banks for Agriculture and Agricultural Cooperatives. It was revealed that $1,199,834$ borrowers have registered and the total borrowed money was 122,280,093,363.23 baht (Comptroller General's Department, Finance Ministry, 2010, online).

Chonburi Community Study and Development Center, under the Community Development Institute, has recognized the pressing problems faced by the noninstitutional borrowers. The Center then decided to investigate the models and methods to solve the problem on non-institutional debts with the use of the existing community capital such as the saving groups for production as the leading mechanism. The researcher has selected Ban Pan Din Yen

Saving Group for Production in Tambon Sae O, Wattna Nakorn, Sakaeo Province as a case investigation due to its well-known success in shredding their non-institutional debts (Sri Burapha Community Capital Institute, 2013). In the past 98.10 of the total households or 155 households were deeply in (non-institutional) debt. However their debt problems have been eradicated since 2007, several years before the government started the public debt solution project.

\section{Objectives}

1) To study the conditions and causes of non-institutional debt in the community.

2) To study models, methods and process in community capital management used in non-institutional debt problem solution.

3) To study the management approach in solving community non-institutional debt problem.

\section{Concept, Theory and Related Researches}

3.1 Public Involvement: Public involvement here is best summarized by Passara Charoen (1997) who briefed the term as the opportunity for the groups of people who were once deemed "bureaucratic outsiders" to monitor their resources or institute to respond to their economic and social benefits for their well- being and dignity of their livelihood, to have a voice in decision-making that affects their lives and follow and supervise government relevant activities, and to be selfreliant in locating their facing problems, and dealing with the problems with as little 
involvement from outside organizations as possible.

3.2 Community Capital: 5 categories of community capital (Bureau of Community Capital and Finance Management, Department of Community Development, 2010, p. 11) are:

3.2.1 Human capital refers people of all ages, types, economic, and education backgrounds, privileges, and skills etc,

3.2.2 Social capital refers to social resources people rely on for living their life, which include trust, acceptance, organizations, public networks, civil society, faith, belief, culture and tradition.

3.2.3 Physical capital refers to manmade structures that facilitate human lives or that are used to produce things that support human livelihood, which include public utilities, means of communication, transportation, artifacts, and archeological sites, as well as buildings etc.

3.2.4 Natural capital refers to natural resources and environments that affect the living and livelihood of the community members, which include forests, water sources, mountains, wildlife, minerals, etc.

3.2.5 Financial capital refers to money and opportunity for the people to use money to benefit their life and livelihood, which include cash, savings, benefit from investment, pension, social welfare, and funds.etc.
3.3 Principle of Saving Groups for Production: The Saving Group for Production refers to the gathering of people who know each other well enough to render help to other group members who are in need of help. Since this is the money-involved gathering, it is necessary to understand the nature of this type of groups.

3.3.1 Sense of ownership is formed to solve the community's own pressing problem. It then belongs to everyone not to the government, so it is their responsible to supervise the work, maintain the facilities, and select the best committee members, or working group, to represent and administrate the group.

3.3.2 Self reliance can be started with building habit of saving based on the community member's outstanding characteristics such as honesty, endurance, and patience.

3.3.3 Integrity is based on common characterizes of the Thai people, which include sympathy, caring, and generosity. These characteristics will stabilize the group due to the members' awareness of their responsibility in solving the common problem.

3.3.4 Mutual supervision refers to the member's interest in group activities, movement, and mutual check.

\section{Conceptual Framework}

\begin{tabular}{|l|l|l|}
\hline $\begin{array}{l}\text { Causes of non-institutional debt } \\
\text { 1. Household conditions } \\
\text { 2. Occupations } \\
\text { 3. Household debt }\end{array}$ & $\begin{array}{c}\text { Management from and } \\
\text { process of savings group in } \\
\text { resolving non-institutional } \\
\text { debt } \\
\text { 1. Human development } \\
\text { 2. Capital development } \\
\text { 3. Management } \\
\text { 4. Resource use }\end{array}$ \\
\hline
\end{tabular}

Figure 1 Conceptual Framework

\section{Research Method}

This research employed qualitative methodology.

Population: 110 households with noninstitutional debt, or $70 \%$ of all households in the village (the Ban Pan Din Yen Savings Group for Production)

Informants: The 2 groups of 30 informants were composed of:
1) 11 community leaders and committee members in the Ban Pan Din Yen Savings Group for Production, Moo 9, Tambon Sae Dor, Wattana Nakorn District, Sakaeo Province actively involved in debt resolution.

2) 19 non-institutional borrowers representing borrowers in the Ban Pan Din Yen Savings Group for Production, Moo. 9, Tambon Sae Or, Wattana Nakorn District, Sakaeo Province 
Site of research population: The researchers decided to base their research in the Ban Pan Din Yen Savings Group for Production, Moo. 9, Tambon Sae O, Wattana District, Sakaeo Province which is served by the Chonburi Community Studies and Development Center, because of its success in “capital” management

Data Collection: Data was collected from April 2012-July 2012 using the interview method, as well as observation, note taking, photographing, interview recording and focus group discussion.

Data Verification: Triangulation was used to test the reliability of the data which was collected using a qualitative method. The data was returned to the villagers to confirm correctness and communal acceptability.

Data Analysis: Analytical induction and content analysis were used in the research.

\section{Research Outcomes}

\subsection{Causes of Non-Institutional Debt}

Most of those who settled in Pan Din Yen Village had few financial resources and therefore had to ask local cassava farm owners to advance them fertilizers and pesticides, with the promise of selling them their harvest. The loans and an additional 5\% in interest were deducted. But when harvests were low, these farmers found themselves unable to repay their debts. They had to seek additional loans from local and external moneylenders who charged monthly interest of 5-10\%, which pushed them further into debt. From 1995-1997, their debts grew and were found to range from 5,000 baht $-300,000$ baht. Most of their creditors were local moneylenders, the Bank for Agriculture and Agricultural Cooperatives, and external moneylenders. These loans were used primarily as occupational start-up funds, to buy agricultural equipment, to pay for their children's education, to meet household expenses, and to build and maintain their homes, respectively.

\subsection{Management forms and Process \\ Employed by the Savings Group in \\ Resolving Non-Institutional Debt}

6.2.1 Management forms in noninstitutional debt resolution

The Ban Pan Din Yen Savings Group for Production was found to employ the following management forms.

Procedures

Debt resolution started by recruiting allies in the village who shared the same goals and ideals for resolving the hardships they faced.
Then additional allies from outside the village were approached to share their knowledge and offer advice in reducing poverty and resolving the problem of non-institutional debt. The two groups then discussed the problems and came up with plans for a possible solution. Then the villagers were recruited to join these efforts, and the idea of fostering financial discipline was shared with them. Approval to link the Village Fund to the "Savings Group for Production" was sought so that the Savings Group could serve as the core directive in managing the Village Fund. Then relevant village rules were agreed upon by the villagers.

6.2.2 Steps in the Savings Group's Management Procedure for Resolving NonInstitutional Debt

The management process was divided into 3 steps:

\section{Step 1: Thinking or planning}

In this step, representatives from various local organizations were recruited to be Ban Pan Din Yen Savings Group for Production members, with five local experts as advisors. The Savings Group and the Village Fund were then linked to form one integrated unit in order to strengthen management, and prevent villagers from falling deeper into debt. At this step, the villagers also agreed on the common rules the villagers would observe.

\section{Step 2: Acting}

In this step, the Saving Groups committee members and the advisors approved loans to members, based on the borrowers' participation in the group, and their personal behavior. The rules and regulations were open to adjustment to cover possible loopholes. After approval of the loans, a three member finance committee was assigned to carry out all relevant financial transactions, with benefits to members as a priority.

\section{Step 3: Evaluation}

In this step, the three committee members checked to ensure that the loan money was used for its intended purpose.

6.2.3 Process in the Savings Group management for resolving non-institutional debt

The study revealed the following processes:

1) Human development: Two groups of people were involved in the management process. The first, composed of the Savings Group committee members, was the first target group. The second group was made up of Saving Group members who demonstrated financial discipline and were economical and able to save through compliance with the 5 moral principles. These members also showed 
an understanding of the importance of group participation.

2) Capital development: The Ban Pan Din Yen Savings Group for Production has set up a community business. The members used the loan given to them to generate income by means of a secondary career in addition to their primary occupation as farmers. The money was also used to clear their non-institutional debts.

3) Management: The Savings Group adopted a participatory approach to administration, with 19 committee members recruited from local groups or organizations, and 5 respected experts acting as the Group's advisors. Monthly meetings were convened and all problems relevant to Savings Group administration were brought up for discussion in order to find viable solutions.

4) Resource use: All kinds of community capital were simultaneously mobilized to solve the debt problem. This community capital consisted of: human capital-- willingness and commitment of each individual member and community leaders; social capital-- kindness, generosity, and caring; physical capital-- the village's relatively remote location and the ease of transportation today; natural capitalfertile land, natural water resources, natural food plants; and financial capital-Village Fund and Savings Group for Production.

\subsection{Directions in Managing Community Capital to Resolve Non-Institutional Debt}

The success of the Savings Group in settling non-institutional debt has been credited to the following guidelines for resolving the debt problem:

1) The Savings Group committee members have shown leadership. They have educated themselves and demonstrated a genuine commitment to resolve the problems affecting the villagers as a result of mounting non-institutional debt.

2) Applying the principles of participatory management to unite relevant groups or organizations in the village to create an awareness of shared problems.

3) Management practices in line with on the Savings Group's rules and regulations, which are based on the principles of equality, transparency, and mutual trust among committee members group members.

4) Fostering a savings habit in Group members and the members of their families, and setting a good example as strong, hardworking, thrifty, individuals who live their lives according to the principles of the sufficiency economy.
5) The use of "community capital" for "community economic development" to create jobs and generate income for the community members.

6) Placing emphasis on the use of local "resources' or “community capital”, which includes finance-related capital such as the resources of the Savings Group for Production, village funds, and poverty alleviation funds, as well as non-finance-related ones such as local traditions and local wisdom, while creating awareness of the need to conserve these kinds of community capital to benefit succeed

\section{Discussion of Findings}

The study revealed a number of management guidelines which contributed to the successful resolution of public non-institutional debt by the Ban Pan Din Yen Savings for Production Group. Success started with the leadership skills of the savings group's committee members and the participatory-based administration which created awareness of the pressing nature of common debt problems. This was driven by traditional Thai culture where the concept of seniority is strong, and where it is common practice to extend help to those in need. This cultural practice was in accordance with Chareon Passa's People's Participation (1997) which refers to the public potential for improving the control and distribution of existing resources and means of production in order to benefit people's lives both economically and socially in a manner that respects their dignity as members of society. Passa also discusses the role of public participation in the development of knowledge and local wisdom that is manifested in the decisions people make in how to live their own lives.

In using the Savings for Production Group's regulations, equality was the chief priority. All committee and regular Group members were treated equally, without exception, which led to transparency and mutual trust among the two groups of members. In addition, the habit of saving, perseverance, and a way of life based on the principle of sufficiency economy were commonly upheld by both committee members and regular Group members. In this way, they became models for others struggling to pull themselves out of debt (The Community Development Department, Interior Ministry, 2011).

Since the Savings for Production Group was initially established to find solutions to the problem of non-institutional debt, it was essential to draw up a set of rules and 
regulations, which all regular members and committee members would be required to follow strictly. These coincided with the principles of the Savings for Production Group (cited in www.pdftactory.com)._ The Group, thus, was composed of people who were already well- acquainted with one another and had an indispensable sense of ownership, selfreliance, integrity, and self-monitoring.

\section{Recommendations}

\section{Policy-oriented Recommendations}

1) The follow-up on progress in resolving public debt (non-institutional debt) should be carried out both qualitatively and quantitatively.

2) The Community Development Department should have concrete guidelines in resolving non-institutional debt so that relevant units can recruit support from community finance organizations such as the community financial management institute, savings for production groups, and city and village funds in solving non-institutional debt, and acting as a financing source for non-institutional borrowers, who cannot get a loan from a commercial bank.

\section{Practical Recommendations}

1) Community financial organizations composed of the community financial management institute, savings groups for production, and city and village funds should take active roles in resolving the problem of non-institutional debt of community members.

2) Organizations at both provincial and district levels should encourage units with existing community capital to coorperate in resolving public problems caused by noninstitutional debt

3) The capacity of the saving groups for production should be elevated and developed so that they can serve as a leading core in resolving non-institutional debt nationwide, on the principle of self-reliance.

\section{References}

[1] Ban Pan Din Yen Savings Group for Production. Borrowers' List. Sakaeo. The Savings Groups for Production. 2012.

[2] Bureau of Community Capital and Finance Development, the Community Development Department, Interior Ministry. Community Development Directions in Community Capital Management (for Official use only). Bangkok. 2010.
[3] Bureau of Community Capital and Finance Development, the Community Development Department, Interior Ministry. Manual for Savings Groups for Production. Bangkok: Leolenset. 2009.

[4] The Community Development Department, Interior Ministry. Directions in the Government's Policy on Resolving Non-institutional Debt. No. มท 0407.3/ว.287. February 25, 2011.

[5] The Comptroller General's Office, Finance Ministry. Policy on Resolution of Public Debt (Non-Institutional Debt). Data researched on April 5, 2012, from www debtdb.cgd.go.th. 2012.

[6] The Community Capital Institute of Sri Burapha. Community Capital Management and the Resolution for Non-institutional Debt Ban Pan Din Yen Savings Group for Production, Tambon Sae O, Wattana Nakorn District, Sakaeo Province. Chonburi: The Community Capital Institute of Sri Bureau. 2012.

[7] Passara Chareon. Public Involvement in Government's Performance. Journal of Thailand Public Administration, 1997, 12, p 1-3. 